\title{
Aplicaciones lexicográficas de un corpus de discurso turístico: contextos de uso y definiciones ${ }^{1}$
}

\author{
Julia Sanmartín Sáez
}

Universitat de València (España)

\begin{abstract}
Resumen: En este artículo se propone, como punto de partida, la elaboración de un corpus de discurso turístico, incluido en una base de datos informática diseñada para tal efecto. En una segunda etapa, se analiza, cómo se contextualizan y usan los términos relativos a la tipología de habitaciones en las páginas web de promoción de hoteles, y si se ajustan o no a la definición que de ellos se ofrece en normativas y diccionarios. Esta metodología de trabajo permitirá, entre otros, diseñar futuros glosarios de promoción hotelera que recojan en las definiciones de los términos todos los matices de significado y notas de uso que sean útiles y adecuadas a los posibles destinatarios del glosario. De este modo, el análisis de los contextos de uso será un elemento determinante en el diseño de las definiciones.
\end{abstract}

Palabras clave: corpus, definición lexicográfica y terminológica, discurso de la promoción hotelera, glosario

Title: Lexicographic applications from a corpus on touristic discourse: contexts of usage and definitions

Abstract: This paper proposes, as a starting point, to elaborate a corpus of touristic discourse extracted from a database designed for that purpose. In a further stage, an analysis will be carried out, in order to study the usage and contextualization of terms related to bedroom typologies in hotel web sites, and whether they adapt or not to their definition in current tourism dictionaries and ISO hotel regulations. This methodology allows to design and make hotel promotion glossaries that include the different meaning shades and usage remarks useful and adequate to the glossaries' final users. The analysis of usage contexts is thus a determining element when constructing definitions.

Keywords: corpus, lexicographic and terminological definition, hotel promotion discourse, glossary

i IULMA (Instituto Interuniversitario de Lenguas Modernas Aplicadas). E-mail: julia.sanmartin@uv.es 


\section{Marco teórico y metodología: explotación de un corpus textual}

Para poder analizar el discurso turístico desde diferentes niveles o perspectivas, el lingüista de hoy en día suele partir de muestras de habla empleadas en su contexto de uso; de ahí, la necesidad de compilar textos representativos y reales en una base de datos informatizada que se convierta en el corpus textual de referencia para el estudioso del lenguaje. En este artículo, pretendemos comprobar justamente cómo la confección de un corpus de textos turísticos puede servir como punto de partida para diseñar un glosario de promoción hotelera que incorpore todos los matices del significado de los términos presentes en los textos y pueda servir, entre otros, como herramienta de trabajo para el profesional o experto del sector en cuestión.

Concretamente, en 2009 se elaboró una base de datos (COMETVAL, Corpus Multilingüe de Turismo de la Universitat de València) con documentos procedentes de páginas electrónicas institucionales de promoción de servicios turísticos de la Comunidad Valenciana, tanto en español como en sus respectivas traducciones al inglés y al francés (corpus paralelo, corpus de traducción o bitext); en una segunda etapa, se recogieron textos de páginas electrónicas institucionales y privadas en español de otras comunidades autónomas de España y de Chile, así como documentos originales similares en inglés (de Reino Unido y de Estados Unidos) y en francés (de Francia y de Canadá) (corpus multilingüe y comparable) ${ }^{1}$. En esta etapa, también se incluyeron textos especialmente relacionados con la promoción del alojamiento: páginas de hoteles, servidores de hoteles, etc. De hecho, la construcción e implementación de cualquier corpus textual ${ }^{2}$ queda determinado por las funcionalidades que se desean aplicar a dicho corpus. En este caso, los textos en versión original y sus correspondientes traducciones posibilitaban analizar cuestiones vinculadas al proceso mismo de traducción: desde errores de redacción a las variadas estrategias estilísticas y pragmáticas utilizadas; por el contrario, la inclusión de textos en versiones originales de las distintas lenguas (corpus comparable) obedecía a una doble pretensión:

a) por un lado, estudiar, entre otros aspectos, la variedad de unidades léxicas relacionada con la promoción y organización del alojamiento en las lenguas de referencia y en sus respectivas modalidades geográficas (a modo de una terminología descriptiva y contrastiva);

b) por otro lado, elaborar un glosario multilingüe (a modo de una terminología aplicada o terminografía). Dicho glosario ${ }^{3}$ se limitaría, en principio, al ámbito de la promoción hotelera y tendría presente especialmente los textos destinados al posible receptor del producto turístico (el cliente), dado el tipo de texto recogido (de promoción).

De hecho, la investigación aquí esbozada surge al detectar los candidatos léxicos a formar parte del glosario y diseñar su definición. En un trabajo anterior (Sanmartín y Edo 2011), como experiencia piloto, se identificaron unidades léxicas específicas relativas al concepto de 'habitación' en español e inglés. Se tuvo presente la adscripción de estas lenguas a dos modalidades geográficas distintas, el español de España y de Chile; el inglés de Reino Unido y de Estados Unidos. ${ }^{4}$ Se trataba de observar si existía variación léxica ${ }^{5}$ para poder incorporar estas variantes al glosario.

Una vez identificadas las unidades denominativas en el corpus, se plantea en el estudio actual si los términos detectados se corresponden con los propuestos en las normativas turísticas y con los hallados en los diccionarios generales y especializados (monolingües, bilingües o multilingües) con el fin de precisar:

- Si los términos de las normativas coinciden con el uso real de las voces que designan la tipología de habitaciones en el corpus, tanto en su aspecto formal como en su significado, o por el contrario, si esos usos léxicos no normativos responden a estrategias pragmalingüísticas diversas.

- Si los diccionarios generales documentan estas voces y si las definiciones se ajustan o no al sentido que se les asigna en el cotexto real ${ }^{6}$.

- Si los diccionarios especializados incorporan estas voces y si las definiciones se ajustan o no al sentido que se les asigna en el cotexto real.

Inicialmente, se parte de la estructuración conceptual de 'habitación' (Sanmartín y Edo 2011) indicada a continuación, considerada como una relación abstracta, lógica o genérica vertical (de género o 'tipos de') y de carácter polijerárquico, ya que se van integrando en distintos niveles (Arntz y Picht 1995: 108-113). Se perfiló dicha estructura a partir de la revisión de las distintas unidades léxicas que configuraban este campo nocional, al considerarse todos ellos como integrantes de este campo, ya que poseían el rasgo sémico 'habitación' (metodología semasiológica: del término al concepto). No obstante, se combinó esta perspectiva con el recurso a las descripciones de este mismo campo nocional que figuraban en manuales de especialidad de turismo y normativas (metodología onomasiológica: de los conceptos a los términos) ${ }^{7}$. Reformulamos aquí esa estructura conceptual para el español (Cuadro 1).

Esta tipología se puede ir ampliando si se añaden más tipos de establecimientos, como por ejemplo, los albergues, en los que se pueden encontrar habitaciones privadas o habitaciones compartidas, las cuales ya se han incorporado a este esquema, pero no figuraban en el trabajo anterior (Sanmartín y Edo 2011). ${ }^{8}$

Además, este sistema o representación conceptual permite extraer al menos dos conclusiones: la existencia de diversas unidades léxicas para el mismo concepto y la complejidad de detectar o reconocer algunas de estas unidades. De hecho, en el esquema no se incluyen tres tipos de expresiones o palabras presentes en el corpus: a) determinadas estructuras sintagmáticas compuestas transparentes ${ }^{9}$ (así, habitación con terraza, habitaciones 
con baño o habitación con vistas); b) las próximas al nombre propio (habitación Malvarrosa o habitación AC); у c) las que indican estilos de decoración (habitación clásica o habitación tradicional).

Se consideran solo como unidades denominativas

Cuadro 1

\section{Sistema conceptual y unidades léxicas}

1. Habitaciones según el número (y tipo) de personas que se alojan -sin salón-

1.1. para una persona:

1.1.1. con capacidad para uno: (habitación) individual, (habitación) para una 1 persona, (habitación) single

1.1.2. con capacidad para dos: (habitación) doble de uso individual, (habitación) doble uso single

1.2. para dos personas:

1.2.1. con una cama: (habitación) doble, (habitación) matrimonial

1.2.2. con dos camas: (habitación) doble, (habitación) twin

1.3. para tres personas: (habitación) triple

1.4. para cuatro personas:

1.4.1. para cuatro adultos: (habitación) cuádruple

1.4.2. para dos adultos y dos niños:

1.4.2.1. en una única habitación: (habitación) cuádruple, (habitación) familiar

1.4.2.2. en dos habitaciones comunicadas: kids room, (habitación) familiar

2. Habitaciones con salón

2.1. con salón independiente del dormitorio: suite

2.2. con salón integrado en el dormitorio: junior suite

3. Habitaciones especiales, según los usuarios

3.1. con posibilidad o no de fumar:

3.1.1. (habitación) para fumadores

3.1.2. (habitación) para no fumadores

3.2. para minusválidos: (habitación) minusválidos, adaptadas para minusválidos, (adaptadas) para discapacitados, habilitadas para discapacitados, adaptadas para huéspedes con movilidad reducida, accesibles, para personas con discapacidad fisica

3.3. para personas de negocios: (habitación) ejecutiva

4. Habitaciones, según su ubicación en el hotel:

4.1. comunicadas, conectadas, intercomunicadas

4.2. contiguas

5. Habitaciones, según una escala de servicios y categoría:

5.1. de menor lujo: (habitación) standard / estándar

5.2. de mayor lujo: superior, premium, upper, deLuxe...

6. Habitaciones, según la privacidad del uso:

6.1. habitaciones privadas

6.2. habitaciones compartidas cidas en las normativas o diseñadas por los expertos del sector determinan la existencia de unidades denominativas, aunque su significado sea transparente, como sucede con compuestos nominales como habitación individual o habitación para fumadores, cuyo significado es deducible a partir de la suma de sus dos componentes (habitación + individual). Aun así, hemos descartado, en principio, en esta descripción la inclusión de algunas unidades sintagmáticas anteriores, como habitación con baño, presente en normativas.

Las unidades léxicas en las normativas y en los repertorios lexicográficos

\section{De las normativas}

Existe una pluralidad de normativas terminológicas de alojamiento turístico, al menos para el español, ya que se documentan normas internacionales con distintas adaptaciones al español peninsular y al español de Chile:

-Norma española UNE-EN ISO 18513 Servicios turísticos. Hoteles y otros tipos de alojamientos turísticos. Terminología ${ }^{10}$, Mayo, 2004.

- Norma Chilena Oficial 2760. Of.2007. Clasificación, calificación y terminología de los establecimientos de alojamiento turístico, del Instituto Nacional de Normalización (2007) ${ }^{11}$, en la que se indica expresamente: "Se ha tomado en consideración la Norma Internacional ISO 18513:2003 Tourism service-Hotel and others types of tourism accomodations - Terminoloy, siendo no equivalente a la misma al tener desviaciones mayores y cambios de estructura y no hay una correspondencia obvia con la Norma Internacional (2007:1)".

Las diferencias entre ambas normativas afectan a los términos empleados. De hecho, aparecen 7 términos coincidentes (como habitación doble o suite), 8 específicos de España (como habitación familiar o dormi- aquellos lexemas (unidades univerbales) o estructuras sintagmáticas (unidades pluriverbales) que se repiten (criterio de frecuencia de coaparición) y parecen responder a conceptos más específicos, no siempre deducibles de la mera adición de los integrantes de la estructura (criterio semántico), como sucede en habitación twin. Ahora bien, en los ámbitos de especialidad las clasificaciones estable- torio para tres o más personas) y 4 singulares de Chile (como single o habitación triple).

También las definiciones presentan divergencias. Así, al comparar en el cuadro 3 la definición de suite, se observa que en la norma chilena se explica la posibilidad de que esté integrada por uno o dos dormitorios; sin embargo, esto no sucede en la norma española, ya que se alude 
únicamente a instalaciones para dormir.

En el caso de España, se aprecian, además, varias normativas en función de cada comunidad autónoma. Explicamos la normativa de tres comunidades como muestra. En la normativa de la Comunitat Valenciana Decreto 206/2010, 3 de diciembre del Consell, por el que se modifican los decretos reguladores del alojamiento turístico en la Comunitat Valenciana, [DOGV6414/10.12.2010] se in-

\section{Cuadro 2}

suite [Chile]: Unidad habitacional de un
establecimiento de alojamiento turístico
compuesta de uno o más dormitorios, baño
privado y un ambiente separado que incluya sala
de estar y área de trabajo (...)
suite [España]: Alojamiento que proporciona
instalaciones para dormir y salón separados y
conectados.

cluye la declaración responsable de actividad, ${ }^{12}$ en la que se indican las siguientes clases de habitaciones en función de si se trata de un hotel o de un hostal, cuyas denominaciones presentamos agrupadas:

Por su parte en la normativa Comunidad de Andalucía, DECRETO 47/2004, de 10 de febrero, de establecimientos hoteleros [publicado en el BOJA 42 del 2 de marzo de 2004] y en la Declaración responsable aparecen las denominaciones indicadas en el Cuadro 4.

Por último respecto a la normativa de la Comunidad de Galicia, se ha revisado la Declaración Responsable de inicio de actividad de establecimientos hoteleros y solicitud de clasificación, publicado por la Xunta de Galicia, Conselleria de Cultura y turismo, en la que figuran los términos que se muestran en el cuadro 5.

Cuadro 3

Doble / Doble con salón o suite jr. / De uso individual / Suite / Individual.
A partir de esta descripción de las normativas, se puede concluir que las normas generales (las normas ISO adaptadas) y las autonómicas coinciden básicamente en los términos y conceptos (expresados a través de las definiciones) con lo registrado en el corpus

- Se contempla como esencial la consideración de las habitaciones en función de su capacidad (individual, triple, doble, cuádruple), su ubicación espacial (comunicadas, contiguas), la incorporación de salón (suite, junior suite) y las condiciones del usuario (instalaciones para discapacitados).

- En las normativas, se recogen términos que no aparecen en el corpus (unidad habitacional) y se incorporan escasas variantes sinonímicas (en Chile, habitación individual, single; en España, habitación individual). En el caso de la adaptación de España de la norma ISO, se detectan voces, como dormitorio para tres o más personas, que no se documentan en el corpus de referencia. En este se registran otras unidades léxicas (habitación triple).

\section{Cuadro 4}

suites son los conjuntos de dos dormitorios dobles con dos cuartos de baño y al menos un salón, acondicionados según cada categoría, con una mayor suntuosidad que el resto de las unidades alojativas.

suite junior es la unidad de alojamiento integrada por un dormitorio doble y un salón, pudiendo estar integrado o no en aquél.

habitación con terraza supone que la superficie de la unidad deberá tener indicada para cada categoría, computándose separadamente la superficie de la terraza. La anchura mínima será de 1,30 metros.

individual / doble / adaptada a minusválidos

\section{Cuadro 5}


- No se reconocen en las normativas todas las unidades establecidas a partir de la categorización de las habitaciones en función de sus servicios y comodidades en una escala de mayor a menor lujo (como habitación deLuxe).

- Las propias normativas discrepan en cuanto a la tipología posible de habitaciones, ya que no todas recogen las mismas distinciones o tipos (habitación con literas / habitación con terraza / habitación con baño).

- Los numerosos sinónimos registrados en el corpus real no se indican en las normativas, lo cual era esperable en textos con una pretensión de estandarización. ${ }^{13}$

- Las definiciones de las normativas son concisas y precisas en el marco de una estructura conceptual concreta y tan solo en la última definición de suite se alude a su suntuosidad.

De los repertorios lexicográficos generales y especializados Si las normativas asumen una función prescriptiva, los diccionarios monolingües explican el sentido de una unidad léxica (bien con una definición lingüística, bien con una definición enciclopédica) y los diccionarios bilingües ofrecen equivalentes léxicos en otras lenguas. Desde esta perspectiva, los primeros se podrían considerar como un repertorio de unidades, con su forma y su concepto, expresado este último en una definición. Estos repertorios asumen una función heurística y pedagógica. La cuestión es comprobar si se ajustan al uso real.

En el caso de los diccionarios especializados, como el monolingüe, Diccionario de Hostelería. Hotelería y turis- mo. Restaurante y gastronomía, cafetería y bar, de Gallego y Peyrolón (2008: 439-440, 767), se recogen solo cuatro denominaciones: habitación, suite, habitación de salida y salón privado; de las que únicamente las dos primeras se documentan en el corpus. Unidades como habitación de salida no aparece en el corpus, dado que dicho corpus se reduce a textos de promoción dirigidos al cliente y el término mencionado (habitación de salida) se vincula a otro tipo de géneros discursivos. Este diccionario resulta de especial interés por la descripción exhaustiva de los tipos de suite que establece (imperial, real, presidencial y junior).

En el caso de los diccionarios especializados plurilingües, se atiende fundamentalmente a la capacidad de la habitación. Así, el Diccionario de términos de turismo $y$ de ocio. Inglés-Español, Spanish-English, de Alcaraz et alii (2006), establece los equivalentes en la lengua meta, los cuales están documentados de algún modo en el corpus revisado. Al tratarse de un diccionario especializado con un número de entradas muy considerable desde la perspectiva de la macroestructura, es esperable que la microestructura sea más reducida. De igual modo, la finalidad del diccionario es ofrecer un equivalente en la lengua de llegada correspondiente. Aun así, la entrada analizada presenta marca de categoría gramatical, restricción de ámbito y ofrece una diversidad amplia de subentradas (Cuadro 7)

El Diccionari d'hoteleria i turisme, del Termcat (2001), clasificado como un diccionario monolingüe en catalán, se ha tenido presente por las definiciones que ofrece (de tipo terminológico) y por los equivalentes que aporta en

Cuadro 6

habitaciones (...) Además de habitaciones individuales o $<<$ singles $>>$ y habitaciones dobles, hay otras como:

salón privado Deberá reunir las condiciones expuestas anteriormente, además de contener un salón, debiendo tener una superficie como mínimo de $12 \mathrm{~m}$, y el salón y dormitorio con teléfono.

suit Se considerarán suite los conjuntos de dos o más habitaciones con sus correspondientes cuartos de baño y al menos un salón.

Suite Vocablo francés que se asigna a la unidad de alojamiento o aposento más lujoso de un hotel. Se define como el conjunto de una o más habitaciones con uno o más cuartos de baño completos, salón y un office. Son las mejores habitaciones de un hotel. Hay suites de distintos tipos y pueden ser denominadas: a) Imperial: Compuesta de dos dormitorios, dos cuartos de baño completos, un salón y un office. b) Real: Compuesta de dos dormitorios, dos cuartos de baños completos, un salón y un office. c) Presidencial: Compuesta de dos dormitorios, un cuarto de baño completo y un salón. d) Junior: Compuesta de un dormitorio, un cuarto de baño y un salón. Los hoteles de cinco estrellas dispondrán de algunas suites y al menos, un 5\% de las habitaciones han de ser suites junior. En los hoteles de cuatro estrellas el 3\% deberá ser junior. 
español. En la tipología de habitaciones se atiende sobre todo a la capacidad y a la ubicación espacial. Los equivalentes presentados coinciden con los que aparecen en nuestro corpus. Destaca por su carácter prescriptivo. A continuación se reproducen algunos de los equivalentes del español, con la definición traducida del catalán al es-
$D R A E$ (2001) se ajusta a este uso más jurídico al considerarlas como 'el conjunto de sala, alcoba y cuarto de baño'. Y en el caso de habitación, únicamente el DEA (1999) diferencia, como subacepción, el empleo de este término en el contexto de un hotel, si bien el ejemplo no sería el más prototípico y esperable.

Cuadro 7

room n/v: ALOJ habitación; puede ser single -individual-, twin [-bedded] -doble con dos camas-, double
-doble con cama de matrimonio-, twin double -triple o cuádruple con dos camas de matrimonio-, duplex
-suite de dos pisos o dúplex-, adjoining / connecting romms -contiguas o intercomunicadas-(...)

pañol (la traducción es nuestra) (Cuadro 8)

En suma, podría decirse que las obras lexicográficas especializadas no son un reflejo del uso real al representar únicamente una parte muy reducida de ese uso.

Por su parte, en los tres diccionarios generales analizados para el español [DUE, Diccionario de uso del español de M. ${ }^{a}$ Moliner (2002); DRAE, el Diccionario de la lengua española de la RAE (2001); y el DEA, el Diccionario del español actual, de Seco, Andrés y Ramos (1999), la conclusión extraída es la escasa presencia de unidades sintagmáticas especializadas. (Cuadro 9)

Solo se recoge el término suite, no definido siempre de una forma acertada si se contrastan las definiciones aquí presentadas con las que aparecen en las normativas. Solo
En definitiva, si el diccionario refleja el "conocimiento" de un posible hablante culto o le ayuda a descodificar textos generales, en el caso que nos ocupa, no recoge ni unidades léxicas simples ni compuestas que aparecen con mucha frecuencia en textos de promoción de hoteles. Por ello y a partir de los datos, queda pendiente la elaboración de un glosario que dé cuenta con exhaustividad de estos términos y ayude a la "defensa" del usuario en materia del ámbito turístico: una aplicación más de la lingüística. Bien es cierto que posiblemente estas unidades sintagmáticas no aparecen en los diccionarios generales porque se considera que su significado es transparente (habitación individual), lo que no siempre sucede con las lexías simples, en especial, cuando se trata de anglicismos (single o twin).

Cuadro 8

habitación Unidad de alojamiento formada, al menos, por un dormitorio y un baño.

habitación comunicada, habitación intercomunicada Cada una de las dos habitaciones situadas al lado con una o dos puertas que permiten el acceso directo de la una a la otra.

habitación contigua Cada una de las dos habitaciones situadas una al lado de la otra sin ninguna puerta que las comunique.

habitación individual Habitación acondicionada para acoger a una persona.

habitación doble Habitación acondicionada para acoger a dos personas y que dispone de una cama de matrimonio o dos camas individuales.

habitación doble de uso individual Habitación doble que es utilizada por una sola persona, a petición suya o por razones de ocupación del establecimiento.

habitación cuádruple Habitación acondicionada para acoger cuatro personas.

habitación triple Habitación acondicionada para acoger tres personas.

suite Conjunto de dos o más habitaciones comunicadas, con los baños correspondientes, y al menos un salón. 
Cuadro 9

\begin{tabular}{|c|c|c|c|}
\hline & DRAE & MOLINER & SECO \\
\hline habitación & $\begin{array}{l}\text { 2. f. Lugar destinado a } \\
\text { vivienda. } \\
\text { 3. f. En una vivienda } \\
\text { cada uno de los } \\
\text { espacios, entre tabiques } \\
\text { destinados a dormir, } \\
\text { comer, etc. } \\
\text { 4. f. dormitorio }\end{array}$ & $\begin{array}{l}\text { 4. f. En sentido } \\
\text { restringido, cada uno de } \\
\text { los departamentos en } \\
\text { que está dividida una } \\
\text { vivienda; se excluyen } \\
\text { generalmente la cocina, } \\
\text { el cuarto de baño y } \\
\text { cualquier otro no } \\
\text { destinado a permanecer } \\
\text { en él: Un piso de siete } \\
\text { habitaciones, cocina y } \\
\text { dos cuartos de baño. }\end{array}$ & $\begin{array}{l}\text { 3. En una vivienda u } \\
\text { edificio: Parte separada } \\
\text { del resto mediante } \\
\text { tabiques y que no está } \\
\text { destinada a servir de } \\
\text { paso. b) } \quad \text { Esp. } \\
\text { Dormitorio u otra } \\
\text { habitación no dedicada } \\
\text { a servicios. c) En un } \\
\text { hotel u establecimiento } \\
\text { similar: Dormitorio: } \\
\text { Hotel de lujo necesita } \\
\text { mozo de habitación. }\end{array}$ \\
\hline suite & $\begin{array}{l}\text { 1.f. En los hoteles, } \\
\text { conjunto de sala, alcoba } \\
\text { y cuarto de baño. }\end{array}$ & $\begin{array}{l}\text { 2. f. Alojamiento de } \\
\text { hotel que incluye dos o } \\
\text { más habitaciones } \\
\text { comunicadas entre sí. }\end{array}$ & $\begin{array}{l}\text { 1. f. En un hotel u } \\
\text { establecimiento similar: } \\
\text { Conjunto } \\
\text { habitaciones } \\
\text { comunicadas entre sí, } \\
\text { que se alquilan a un } \\
\text { cliente. Ya ves el hotel } \\
\text { en que está, con una } \\
\text { suite que ni un jefe de } \\
\text { estado. }\end{array}$ \\
\hline
\end{tabular}

También cabe precisar que, aunque el usuario, lego en el ámbito del turismo, pueda inferir un cierto significado de las estructuras sintagmáticas, en absoluto conoce toda la reglamentación de tipo urbanístico que establece las medidas de una habitación, por ejemplo, y que quizá podría incluirse de algún modo en el glosario. Algunas cadenas hoteleras indican este dato (las medidas de la superficie de la habitación) en su información publicitaria.

De este modo, se plantea qué tipo de definición ${ }^{14}$ requiere el lector del texto lexicográfico. Sin abordar las diferentes tipologías planteadas en torno a esta cuestión, compartimos la distinción clásica de M. Seco (1987: 31-32) entre definición lógica (identifica de un modo inequívoco el objeto a partir de unos rasgos positivos y como miembro de una clase cerrada), la definición lexicográfica (enumera los rasgos semánticos más importantes y suficientes para distinguirlo de otras unidades léxicas) y la definición enciclopédica (explica de un modo profuso la realidad nombrada por el lexema). De hecho, la definición del Diccionari d'hoteleria i turisme, del Termcat (2001) responde al tipo de definición lógica (o terminológica), los diccionarios generales plantean más bien una definición lexicográfica y el Diccionario de Hostelería. Hotelería y turismo. Restaurante y gastronomía. Cafetería y bar, de Gallego y Peyrolón (2008), una definición enciclopédica. En el caso de las definiciones generales, el propio Seco (1987: 32) reconoce que la "suficiencia" de rasgos "no es la misma para una persona de cultura media que para un especialista o un estudioso de la rama del saber que versa sobre el objeto definido". En cualquier caso, consideramos, por un lado, 
que la adecuación de la definición dependerá siempre del lector al que se dirige el producto lexicográfico, como también postula L. F. De Lara (2004: 40): "la selección que hace un lexicógrafo de los tipos de definiciones que convienen al diccionario que se propone elaborar depende de la cuestión inicial de la lexicografía: para qué público escribe el diccionario y cuáles son sus necesidades en relación con el conocimiento del léxico de una lengua". Por otro lado, compartimos también la defensa de un tipo de definición de carácter explicativo, esto es, "la que se construye a partir del análisis semántico de los usos de un vocablo en período de tiempo que se pueda considerar sincrónico, y tiene por objeto aclarar todos los elementos pertinentes a la comprensión de los significados del vocablo. (...) Para que la definición pueda servir a la comprensión de cada uso de un vocablo, necesita atender a los más sutiles matices del significado, con el objeto de que funciones como un dispositivo de interpretación” (...) (De Lara 2004: 56). Esto es, asuma una función heurística.

\section{Las unidades léxicas en su contexto de uso: el cor- pus}

El contexto de uso en que se insertan las unidades léxicas precisa el sentido correspondiente. Cabe matizar que las unidades se ubican en géneros textuales o subgéneros concretos: como ya hemos señalado voces como unidad habitacional solo se recoge en el género discursivo de las normativas o términos como habitación disponible no aparece en géneros de promoción. A continuación, se describen las unidades léxicas con un cotexto representativo. La clasificación parte de la estructura nocional descrita en la tabla anterior. De algún modo, el análisis que realizamos combina nociones procedentes del ámbito lexicológico (lexicográfico) y del terminológico (terminográfico). El léxico aquí estudiado forma parte de las unidades de conocimiento "especializado" del ámbito turístico y, de hecho, se incluyen como términos en normas nacionales e internacionales, en las que se intenta una definición a partir de su ubicación en una estructura nocional. Ahora bien, estas unidades léxicas se ubican en textos de promoción y se dirigen a un público lego, con lo cual trascienden ese primer uso normativo (Calvi y Bonomi 2008: 182). Desde esta perspectiva, estas lexías que estaban perfectamente definidas, casi por oposición, en estructuras claras y eran objeto de definición terminológica (o lógica), como la postulada por organismos como el Termcat (2009), se integran en la competencia léxica de un hablante no especializado, que elabora estos conceptos o los infiere a partir de los contextos de uso. Esto es, más allá de estructuras rígidas, con univocidad y sin connotaciones, los términos documentados adquieren unos valores y connotaciones a partir de los contextos de uso:

Especialista $\rightarrow$ especialistas (textos normativos: unidades terminológicas con univocidad y sin connotaciones: definición lógica o terminológica)

Especialista $\rightarrow$ profano (textos de promoción: unidades léxicas sinonímicas con matices y connotaciones: definición lingüística / enciclopédica de las unidades léxicas)

Véase que aquí se proponen dos niveles distintos: el nivel del especialista y el nivel del profano; y quizá sería conveniente insistir en que en las distintas normativas del sector turístico se aboga por un uso de los términos (unívoco) y sin connotaciones, el cual no se ajusta al uso real en los textos. De este modo, el ideal de la terminología "normativa y prescriptiva" choca con el modelo más comunicativo de la terminología, reconocido ampliamente en el panorama de estudios actuales (Cabré 1993, 2001). Por supuesto, el sector turístico no escapa de este doble nivel de enunciación. La revisión de las definiciones de los textos normativos, de los diccionarios especializados y de la lengua general, y de su uso real en los textos intenta demostrar este doble nivel.

Las unidades léxicas presentadas comparten todas ellas el mismo rasgo de significado (llámese sema, atributo o característica esencial, entre otras, en función del modelo teórico aplicado), no reproducido en la definición ('habitación de un establecimiento hotelero y destinada al alojamiento turístico'), insertas en un cotexto de uso a modo de ejemplo (indicado en letra cursiva) y con todas las inferencias que se deducen del uso real ${ }^{15}$. Las palabras que aparecen entre paréntesis pueden incorporarse o no como formantes de esa unidad léxica. No se reproduce de nuevo el esquema conceptual, ya presentado, en el que se organizan las unidades léxicas, según sus características o rasgos considerados como esenciales (Arntz y Picht 1995: 82). Existe cierta sinonimia (distintas unidades léxicas), si bien se observa que estas unidades tienden a utilizarse de forma preferente por zonas geográficas, tal y como se ha establecido con la marca correspondiente Esp. (España) o Am. (En el caso de Chile). Esto no quiere decir que no se pueda documentar más allá de este límite territorial. ${ }^{16}$ Únicamente algunas de estas unidades se reconocen en las normas ISO, lo que se señala con un asterisco (*). Por cuestiones de espacio, solo analizaremos aquí las unidades de los dos primeros apartados al considerarse como más representativas y esenciales.

\section{Capacidad de ocupantes de la habitación}

Este concepto se emplea sobre todo para efectuar reservas en coaparición con voces singulares de ese tipo de documento textual (reservas, plazas, régimen de alojamiento, disponibilidad, etc.) y del mismo campo léxico, como se comprueba en los ejemplos (así, habitación individual convive con doble o triple en el mismo enunciado). Sin embargo, en muchas ocasiones la capacidad de la habitación se indica únicamente en la reserva a partir de la selección numérica de las personas: 1, 2, 3, 4, etc.

En el caso de las habitaciones para una persona, surge una nueva subordinación jerárquica a partir de la característica esencial ('capacidad de la habitación'), lo que permite establecer la siguiente diferenciación en el cuadro 11: con capacidad al menos para una persona: (habitación) individual, (habitación) para una 1 persona, 
(habitación) single; con capacidad al menos para dos personas: (habitación) doble de uso individual, (habitación) doble uso single

Desde el punto de vista teórico, resulta compleja la con- precio de la habitación sea superior al de una habitación individual, lo cual no se infiere del cotexto, pero aparece este dato cuando se busca el precio del alojamiento. En ambos casos se plantea la cuestión de si la 'mayor como-

Cuadro 10

(habitación) individual (Esp.) Reservas: Individual, doble de uso individual, doble (2 camas), doble (1 cama), doble, cuádruple, habitación ejecutiva.

single* (Am.) Tipo de Habitaciones: single Doble Triple Cuádruple

habitación para 1 persona (Esp.) Habitación Upper para 1 persona con minibar, baño privado con ducha, caja de seguridad, TV satelite y LCD, teléfono, aire acondicionado, complementos de baño, calefacción, suelo de madera.

(habitación) doble uso individual (Esp.) Habitación Doble uso individual Habitación con cama de 1,35 metros de ancho, entre otras comodidades detalladas en el apartado de características.

(habitación) doble uso single (Esp.) Reservas: habitación Doble uso single / habitación triple / habitación doble

(habitación) doble para 1 persona (Esp.) Habitación Doble para 1 ó 2 personas con tratamiento superior que incluye cocktail de bienvenida, prensa en la habitación o acceso a la planta ejecutiva.

Cuadro11

(habitación) doble* $f$. Habitación Deluxe. Confortable habitación doble de lujo de aproximadamente unos 35 metros cuadrados.

(habitación) twin f. (Esp.) Habitación AC Twin. Los huéspedes del hotel AC Ciudad de Sevilla disponen de $25 \mathrm{~m} 2$ con dos camas juntas individuales de $1 \mathrm{~m} \times 2 \mathrm{~m}$, cuenta con los mismos servicios que la habitación $A C$.

habitación matrimonial (Am.) Habitación matrimonial Mar. Equipada con una cama (1.80 x2.ooMT), calefacción independiente, cerradura electromagnética con cierre de seguridad, Internet inalámbrico de alta velocidad, telefonía con discado directo nacional e internacional con correo de voz, TV cable, caha de seguridad con capacidad para netbook y cierre electrónico, servicio de mucama y baño compleo en suite (...).

sideración de estos sintagmas nominales como unidades compuestas, dada su transparencia semántica y su falta de idiomaticidad. Sin embargo, se observa una repetición de la estructura sintagmática y una clara adscripción a una jerarquía conceptual del ámbito especializado, ya que aparecen en normas de reglamentación, por ejemplo.

El cotexto también permite inferir que la habitación doble de uso individual se solicita con la finalidad de conseguir una habitación de dimensiones mayores y una comodidad superior; o, en ocasiones, porque no quedan habitaciones individuales libres. Esto supone que la tarifa o didad' y 'precio superior' son datos que deberían aparecer o no en una definición. De nuevo, señalamos que todo dependerá de qué tipo de definición realicemos. El análisis del corpus también permite apuntar que existen variantes sinonímicas distintas: el español peninsular emplea con mayor frecuencia el término patrimonial (individual) y el español de Chile opta por el anglicismo (single). Resulta curioso que el término single apenas se documente en el español de España y, en cambio, aparezca en este compuesto sintagmático. En cualquier caso, es menos frecuente que doble uso individual. El anglicismo suele aña- 
dir una connotación de modernidad ${ }^{17}$ o "esnobismo", de ahí su uso frecuente en distintos ámbitos a pesar de contar con los equivalentes patrimoniales correspondientes.

En el caso de las habitaciones ocupadas por dos personas también se constata una nueva jerarquía en función del tipo de cama, tal y como se comprueba en el cuadro 12: sin especificar el tipo de cama: (habitación) doble, con dos camas: (habitación) twin, con una cama: (habitación) matrimonial

A diferencia del concepto anterior, en este caso la jerarquización se realiza en función del tipo de cama que se habilite en la habitación; por ello, no existe una sinonimia real, dado que las unidades léxicas presentan características esenciales distintas. De hecho, en la norma ISO-UNE se indican dos términos distintos: habitación doble y habitación doble (con camas separadas). No obstante, sería necesario comprobar con más datos del corpus si en Chile existe un uso implícito de habitación doble (dos camas) y habitación matrimonial (una cama). En España, en cambio, aparece habitación doble (sin especificar camas) y habitación twin (con dos camas), como se demuestra, por ejemplo, en las habitaciones de un hotel español: individual, doble, twin, triple. También cabe tener presente que en muchas ocasiones la denominación que aparece en los textos de promoción (Habitación Deluxe, Habitación $A C)$ responde a estrategias publicitarias para llamar la atención del posible cliente y no se trata, en verdad, de una denominación técnica. En el marco de las posibles estrategias publicitarias, surge el anglicismo twin, cuyo significado no resulta tan transparente a muchos hablantes peninsulares, por lo que causa, por ejemplo, preguntas entre los internautas en distintos foros para conocer su significado (Cuadro 12).

Por último, resulta llamativo el contraste entre el sin-
No obstante, este matiz semántico que aporta kids room debe ser comprobado con más voces, ya que su presencia en el corpus es sumamente escasa. Por supuesto, el precio de la kids room es superior al de la family room. Tan solo family room y habitación familiar se pueden considerar como verdaderos sinónimos, en los que vuelve a convivir el término patrimonial (estandarizado) y el anglicismo. También se ha recogido la perífrasis habitación para 4 personas, con la descripción textual concreta en la que se explica que se trata de dos adultos y dos niños: Habitación para 4 personas con cama doble +2 camas para niños con: climatización automática, amplia mesa de trabajo, televisión a color con canales de pago y satélite, caja fuerte, con una conexión para voz y otra para datos, WI-FI (con cargo) y un secador de pelo en el baño privado.

Por último, destaca la falta de coherencia entre las unidades propuestas en la Norma ISO-UNE, dormitorio para tres o más personas, y el corpus real: no hay ninguna documentación de este término.

\section{Habitaciones, según el tipo de espacios habitables}

En todos los textos de promoción los enunciados que siguen al término objeto de estudio adquieren una doble función: por un lado, concretan el significado del término; por otro, promocionan el tipo de alojamiento ofertado a partir, entre otros, de adjetivos valorativos positivos (espaciosa, amplia, idónea, etc.) o de sustantivos relacionados con aspectos sensitivos (placer, comodidad, etc.). (Cuadro 14)

En el cotexto se infiere la diferencia conceptual entres estas dos modalidades, suite y suite junior (con el salón incorporado o no). ${ }^{18}$ En el segundo ejemplo, además, se comprueba que el término suite se puede combinar con el adjetivo ejecutiva (que en el esquema inicial responde

\section{Cuadro 12}

Hola a todos quiero hacer una reserva a un hotel a traves de su pagina web, me encuentro que tengo la
opcion twin, doble o doble (ocupacion sencilla). Que diferencia hay entre unas y otras? Supongo que la de
ocupacion sencilla debe ser individual, pero twin y doble??? Gracias Eva
$\underline{\text { http://www.foro.geoplaneta.es/default.aspx?g=posts\&m=59887 }}$

tagma habitación matrimonial (y cama matrimonial), en Chile y cama de matrimonio en España. Constituyen formas sintagmáticas diversas, que aluden al tamaño de la cama a partir del vínculo institucional del matrimonio. En España las habitaciones de hotel nunca son matrimoniales.

En este apartado de capacidad de la habitación, agrupamos las habitaciones para tres y cuatro personas, ya sean adultos o niños (Cuadro 13)

Como se ha indicado en la estructura, existen conceptos distintos en función de la capacidad (tres personas, cuatro personas, dos niños y dos adultos) y del tipo de habitación (una única habitación o habitaciones comunicadas). a un tipo de modalidad de habitación en función del destinatario) y con adjetivos como doble o complementos del nombre, de lujo, que parecen presentar una nueva denominación. Este tipo de estructura sintagmática, no catalogada en las normativas, responde a un propósito estratégico de llamar la atención del posible cliente y ofrecer un producto más atractivo.

En suma, todos los comentarios anteriormente expuestos deberían incluirse de algún modo en la entrada de un futuro glosario, aunque fuera separando la definición de tipo terminológico de la enciclopédica para que la lectura de la definición abarcara todos los aspectos posibles y resultara heurística para el lector, profano en la materia. 
Cuadro 13

(habitación) triple* $f$. Triple Habitación con capacidad de 2 a 3 personas. Todas las habitaciones triples están cuidadas al mínimo detalle y decoradas con un estilo moderno. Con acabados de calidad y con todo lo necesario para asegurar tu confort y descanso.

(habitación) cuádruple* $f$. Tipo de Habitaciones Single Doble Triple Cuádruple

family room $f$. Hotel para niños en Madrid. Venga con sus hijos a nuestro hotel. Hotel con habitaciones para niños, disponemos de multitud de atenciones y espacios para sus juegos y entretenimiento. Resérvenos una KIDS ROOM donde estarán cómodamente instalados en una habitación independiente, comunicada con la suya. O si lo prefiere la FAMILY ROOM, una habitación pensada para ser compartida con sus hijos

habitación familiar* $f$. Las habitaciones familiares de Expo Hotel Valencia están compuestas por dos habitaciones ejecutivas comunicadas: una de matrimonio para los papis y la otra con dos camas para vuestros hijos. La ocupación máxima habitación es de 4 adultos +1 niño. // El hotel dispone de 47 habitaciones familiares. Todas disponen de cama de matrimonio y sofá-cama doble para 2 niños con edades comprendidas entre 2-12 años, con baño completo, terraza, aire acondicionado y calefacción, televisión vía satélite y teléfono.

kids room $f$. Amplia habitación con habitación con habitación independiente comunicada. Habitación amplia con mucha luminosidad, en la qué podrá disfrutar junto a su familia a la vez que sus hijos pueden estar jugando en otro espacio de la habitación con su propia independencia, e incluso pueden jugar en la sala infantil del hotel (fines de semana).

Cuadro 14

suite junior* Suite doble de lujo muy espaciosa, de aproximadamente 60 metros cuadrados, con una amplia área de trabajo.

suite (ejecutiva) Suite doble de lujo con unos 80 metros cuadrados y salón independiente. Es la suite idónea para altos ejecutivos que desean comodidad y espacios separados para descansar y trabajar. Y para los que el trabajo no está reñido con el placer, disponemos también de Suite Ejecutiva con terraza privada y Jacuzzi.

De un modo sintético, la información que debería aparecer sería la que indicamos para la voz suite junior:

suite junior f. [marca gramatical] Unidad de alojamiento de un establecimiento hotelero, compuesta por un espacio único, en el que se integran juntos un dormitorio doble y un salón, y un cuarto de baño.

Observ.: Término estandarizado en la normativa española. La junior suite se diferencia de la suite en que salón y dormitorio no están separados. Al igual que otros términos similares, se puede encontrar combinados con otros adjetivos como ejecutiva, doble, clásica...que añaden matizaciones semánticas relativas al posible usuario o decoración de la habitación, entre otras. El precio, mayor tamaño, comodidad y suntuosidad son superiores otro tipo de habitaciones no consideradas como suite.

Contexo de uso real (reproducción de un ejemplo ilustrativo) Las Junior Suites están concebidas para aquellos que buscan un mayor espacio y por lo tanto una mayor comodidad durante su estancia en el Evenia Zoraida Park. Estas Suites ofrecen un espacio extra, baño y dos terrazas con vistas al mar o a la zona ajardinada del hotel 


\section{Conclusiones}

El corpus, considerado como un conjunto representativo de datos lingüísticos, y los programas informáticos de extracción de términos y colocaciones permiten comprobar los usos reales, las denominaciones, y las posibles estructuras conceptuales de los dominios especializados. No obstante, la selección correcta del corpus, en función de los objetivos planteados, resulta fundamental para valorar los resultados. En este sentido, consideramos que la estructura conceptual analizada en la investigación llevada a cabo a modo de ensayo piloto podría ser perfilada de otro modo si en el corpus se incorporan más tipos de establecimientos hoteleros y un corpus más amplio.

Sin embargo, los datos extraídos confirman la hipótesis de partida, la existencia de cierta variedad denominativa en el español de las páginas electrónicas de promoción; una variedad que no se ajusta del todo ni a las normativas ni a los diccionarios generales y especializados existentes.

Por ello, planteamos, desde la lingüística aplicada, el uso de los datos obtenidos en la investigación no solo para conocer desde el punto de vista teórico la configuración de estos campos nocionales, sino para aprovechar los conocimientos en la mejora de los propios servicios turísticos. Este último puente entre la lingüística y la sociedad es el eslabón que nos falta transitar. Se trataría de redactar de un modo sintético las divergencias entre norma y uso con el objetivo de que las autoridades competentes adopten las medidas, si tal y como indican en las normativas desean realmente "garantizar" los derechos de los usuarios de los servicios turísticos al reservar o contratar las unidades habitacionales.

Cabe insistir en que todo lo anteriormente expuesto supone una aproximación lingüística (aplicada) al ámbito turístico, que exigiría su complementación con la labor del experto en turismo. Se abren nuevas vías a la interdisciplinariedad, que en este caso nos parece obligada. Así pues, quede este texto como una propuesta abierta, un puente entre disciplinas para mejorar en la medida de lo posible el discurso del turismo. Un puente que transita por la defensa de definiciones explicativas que asuman una función heurística y que recojan los datos o rasgos de significado a partir de los cotextos de uso real. En este sentido, en las entradas lexicográficas se incluirían todos aquellas características de significado que permitieran al lector no solo entender en qué tipo de habitación se aloja sino incluso conocer las medidas y tamaños que debe tener.

\section{Bibliografía}

Alcaraz, Enrique et al

2006 Diccionario de términos de turismo y de ocio. Inglés-

Español, Spanish-English. Barcelona: Ariel, (1 ${ }^{\mathrm{a}}$ ed. 2000).

Arntz, Reiner / Pitch, Heribert

1995 Introducción a la terminología. Madrid: Fundación
Germán Sánchez Ruipérez.

Baker, Mona

1995 "Corpora in Translation Studies: An overview and some suggestions for future research". Target, 7, 223243.

Blasco, Albert (coord.)

2006 Manual de gestión de producción de Alojamientos y Restauración. Madrid: Síntesis.

Cabré, Teresa

1993 La terminología. Teoría, metodología y aplicaciones. Barcelona: Antàrtida-Empúries.

Cabré, Teresa

2001 "Sumario de los principios que configuran la nueva propuesta teórica”, en: Cabré, T. / Freixà, J. (Eds) La terminología científico-técnica, Barcelona: IULA-Universitat Pompeu Fabra.

Calvi, Maria Vittoria.

2006 Lengua y comunicación en el español del turismo. Madrid: Arco Libro S.L.

Calvi, Maria Vittoria / Bonomi, Milin

2008 "El lenguaje del turismo: de los textos especializados a la Comunidad del viajero". En Navarro, C. et al (Eds.) La comunicación especializada. Berna: Peter Lang, 181-214.

Caravedo, Rocío

1999 Lingüistica del corpus. Cuestiones teórico-metodológicas aplicadas al español. Colección: Gramática española, enseñanza e investigación. Apuntes metodológicos. Josse de Kock. I. 6. Salamanca: Universidad.

Freixà, J. / Kostina, I. / Cabré, Teresa

2002 "La variación terminológica en las aplicaciones terminográficas", en: Actas del VIII Simposio Iberoamericano de terminología, Cartagena de Indias

Gallego, Jesús / Peyrolón, Ramón

2009 Diccionario de hostelería. Hotelería y turismo, restaurante y gastronomía, cafetería y bar. Madrid: Paraninfo.

Hallebeek, Jan

1999 "El corpus paralelo", http://www.sepln.org/revistaSEPLN/revista/24/24-articulo5.pdf

Lara, Fernando

2004 De la definición lexicográfica. México: El Colegio de México.

Medina, $\mathrm{M}^{\mathrm{a}}$ Aantonia

2003 "La microestructura del diccionario: la definición".

En Medina, Mªntonia (Coord.) Lexicografía española. Barcelona: Ariel, 127-146.

Moliner, María

2002 Diccionario de uso del español. Madrid: Gredos.

Pérez, Chantal

2002 Explotación de los córpora textuales informatizados para la creación de bases de datos terminológicas basadas en el conocimiento, Vol.18, Estudios de Lingüística del Español (ELiEs), [http://elies.rediris.es/ elies18/index.html

Real Academia Española

2001 Diccionario de la lengua española. Madrid: Espasa. 
Sanmartín, Julia

2011 "Unidad y variación en el español del turismo: las páginas web de promoción de hoteles de España y de Chile". En Calvi, Mª.V. / Mapelli, G. (Eds.) La lengua del turismo. Géneros discursivos y terminología. Berna: Peter Lang, 335-358.

Sanmartín, Julia

2012 "De las normativas turísticas a las páginas electrónicas de promoción de hoteles: la clasificación hotelera desde la perspectiva lingüística". En Sanmartín, J. (Ed.) Discurso turistico e Internet. Madrid: Lingüística Iberoamerica, 81-124.

Sanmartín, Julia / Edo, Nuria

2011 “Análisis del concepto 'habitación' en un corpus bilingüe español-inglés de páginas electrónicas de promoción hotelera”. En Carrió, Mª L. / Candel, M.A. (Eds.) Actas del III Congreso Internacional de Lingüistica de Corpus. Las tecnologías de la información y las comunicaciones: presente y futuro en el análisis de los corpus. Valencia: Editorial Universidad Politécnica de Valencia, 299-319.

Santos, Javier

2011 "El glosario Linguaturismo". En Calvi, Mª.V. / Mapelli, G. (Eds.) La lengua del turismo. Géneros discursivos y terminología. Berna: Peter Lang, 249-272.

Seco, Manuel

1987 Estudios de lexicografía española, Madrid, Paraninfo.

Seco, Manuel / Andrés, Olimpia / Ramos, Gabino 1999 Diccionario del español actual, Madrid: Aguilar.

Termcat

2001 Diccionari d'hoteleria i turisme. Barcelona: Edicions 62.

Termcat

2009 La definició terminológica. Barcelona: Eumo Editorial.

Torruella, José / Llisterri, Joaquim

1999 "Diseño de corpus textuales y orales". En Blecua, J, Claveria, G. Sánchez, C. / Torruella, J. (Eds.) Filología e informática. Nuevas tecnologías en los estudios filológicos. Barcelona: Editorial Milenio, 45-77.

\section{Normativas legales consultadas}

Instituto NACIONAL DE NORMALIZACIÓN (2007) Clasificación, calificación y terminología de los establecimientos de alojamiento turístico, Norma Chilena Oficial 2760. Of.2007 http://www.calidadturistica.cl/archivos/alojamiento/nCh02760-2007-047.pdf

NORMA ISO (2004) UNE-EN ISO 18513 Servicios turísticos Hoteles y otros tipos de alojamientos turísticos Terminología. Madrid: AENOR.

DeCRETo 206/2010, 3 de diciembre del Consell, por el que se modifican los decretos reguladores del alojamiento turístico en la Comunitat Valenciana, [DOGV $6414 / 10.12 .2010]$

DECRETO 47/2004, de 10 de febrero, de establecimientos hoteleros [publicado en el BOJA 42 del 2 de marzo de
2004]

Ley 14/2008, 3 de diciembre, de turismo de Galicia [publicado en BOE del 16 de marzo de 2009]

DECRETO 492/2008, de 11 de noviembre, de modificación del Decreto 47/20004, de10 de febrero, de Establecimientos hoteleros [publicado en el BOJA 243 del 9 de diciembre de 2008].

DECRETO 47/2004, de 10 de febrero, de establecimientos hoteleros [publicado en el BOJA 42 del 2 de marzo de 2004.

Ley 14/2008, 3 de diciembre, de turismo de Galicia [publicado en BOE del 16 de marzo de 2009] http://www. boe.es/boe/dias/2009/03/16/pdfs/BOE-A-2009-4367.pdf

DECRETO 267/1999, do 30 de septiembre, por el que se establece la ordenación de los establecimientos hoteleros [publicado en el Diario Oficial de Galicia lunes, 18 de octubre de 1999]

Ley 3/ 1998 de 21 de mayo, de Turismo de la Comunidad Valenciana [publicado en DOGV 3248, de 22 de mayo de 1998]

DECRETO 153/1993, de 17 de agosto, del Gobierno Valenciano, regulador de los establecimientos hoteleros de la Comunidad Valenciana [publicado en DOCV 2100, de 10 de septiembre de 1993]

DECRETO 206/2010, de 3 de diciembre, del Consell, por el que se modifican los decretos reguladores del alojamiento turístico en la Comunidad Valenciana, [publicado en DOCV 6414, de 10 de diciembre de 2010]

ISO (2004) UNE-EN ISO Servicios turísticos Hoteles y otros tipos de alojamientos turísticos Terminología. Madrid: AENOR.

\section{Notas}

1 Este texto se ha elaborado en el marco del Proyecto de investigación, Análisis léxico y discursivo de corpus paralelos y comparables (español-inglés-francés) de páginas electrónicas de promoción turística, financiado por el Ministerio de Ciencia e Innovación. Referencia: FFI2011-24712.

2 El término corpus comparable se emplea con diferentes sentidos; así, para unos como Baker (1995) o Hallebeek (1999) se trata de corpus en una lengua en versión original y traducciones a esa misma lengua para poder "comparar" las versiones originales con sus correspondientes traducciones. Por el contrario, para otros, como Torruella y Llisterri (1999), se considera como una selección de textos similares en cuanto a sus características en más de una lengua o en más de una variedad.

3 La reflexión sobre los principios metodológicos que guían la construcción de los corpus, sobre la funcionalidad y tipología, o sobre las herramientas informáticas utilizadas, ha dado lugar y posibilitado la articulación de una disciplina aplicada denominada Lingüistica de Corpus con sus publicaciones, congresos y asociaciones. Insistimos en la importancia de la palabra aplicación, dado que la compilación de un corpus textual siempre suele estar concebida para utilizarse con un fin concreto. En este sentido, R. Caravedo (1999: 19) afirma: “denomino 
lingüistica del corpus a toda orientación que, en la formulación y en el desarrollo de su programa de investigación (comprendidos la teoría y el sistema de corroboraciones o refutaciones desprendido de la actividad analítica), depende de la observación de un conjunto de datos extraído de la producción real de los individuos, y ordenados según criterios metodológicos diferentes pero explícitos de investigación.” Véase este estudio para un acercamiento a la disciplina. También puede ampliarse con el trabajo de Pérez (2002). Resulta de interés la página web de la Asociación Española de Lingüística de Corpus, AELINCO http://www.um.es/aelinco/

4 Conocemos la existencia de un glosario de gestión hotelera bilingües, español-italiano, coordinador por Luis Javier Santos López de la Universidad de Milán en el marco del proyecto Linguaturismo, inédito todavía, con 382 términos (Santos 2011).

5 En el caso del español de España, se tomaron como corpus las páginas electrónicas privadas de hoteles de cinco estrellas y de cuatro estrellas de tres Comunidades Autónomas (Galicia, Andalucía y Valencia). Se incorporaron los hoteles de esta categoría porque son los que, en principio, establecen mayor diversidad de habitaciones. Y del español de Chile, país seleccionado por la accesibilidad a las normativas turísticas y a las páginas privadas de promoción, se vaciaron los hoteles de estas mismas categorías de tres "centrales de reservas" en línea: RutaChile.com http://www.rutaschile.com/; Santiago de Chile.com http://www.santiagodechile.com/; Welcomechile. com http://www.welcomechile.com/. Una vez implementada la base de datos con el corpus, se utilizaron los programas informáticos WordSmith y Anconc3.2. para obtener el listado de voces (Word List) y las colocaciones (Cluster) de los términos que considerábamos como pertenecientes al concepto 'habitación' de cada uno de los microcorpus realizados en español e inglés.

6 En un trabajo anterior comprobamos la existencia de diferencias geográficas entre el español de España y de Chile en el ámbito turístico (Sanmartín, 2011).

7 Empleamos el término cotexto para aludir a los enunciados anteriores y posteriores de un enunciado; y la voz contexto para todos aquellos elementos o factores que determinan la situación de uso en un enunciado (emisor, receptor, canal, etc.).

8 Consideramos que la lexicografía especializada y la terminografía devienen metodologías de trabajo complementarias y cuyo uso depende de los objetivos del glosario. También entendemos que esta propuesta de clasificación conceptual podría ser diferente, ya que el esquema es más complejo de lo que en principio aparenta: las unidades habitacionales pueden ser habitaciones o suites, y los conceptos 3, 4, 5 y 6, se pueden y suelen superponer a los dos primeros.

9 Frente al anterior corpus, obtenido de una forma más bien sistemática, aquí hemos ampliado la búsqueda con lo que se llama un corpus ad hoc, en concreto, la búsqueda a través de
Internet de textos que incluyan las voces objeto de análisis. Este método nos ha permitido descubrir más unidades como suite presidencial, no incorporada de momento a esta estructura conceptual, ya que exigiría un análisis más complejo de los tipos de suite.

10 Cuanto más transparente es el significado de una unidad sintagmática, más complejo resulta establecer su individualidad como unidad denominativa. Hemos prescindido de términos como, habitación infantil porque apenas se documenta en el corpus: Dispone de 179 habitaciones distribuidas en 7 plantas: 3 plantas de categoría "hotel", 3 de categoría "club" y una planta "ducal". Asimismo, cuenta con 5 suites reales, 14 junior suites y una habitación infantil En este sentido, la frecuencia de aparición de una unidad en el corpus deviene importante.

11 Los términos de esta norma se pueden consultar públicamente en Terminesp, en el marco del Portal: Terminología de la Wikilengua (Fundéu) [http://www.wikilengua.org/index.php/ Portal: Terminolog\% C3\%ADa.]

12 http://www.calidadturistica.cl/archivos/alojamiento/nCh02760 -2007-047.pdf

13 Las normativas autonómicas halladas en materia turística se adaptan al ordenamiento jurídico español, que incorpora la Directiva 2006/123/CE del Parlamento Europeo del Consejo, de 12 de diciembre de 2006, relativa a los servicios en el mercado interior, que introduce los principios generales de libertad de establecimiento y la libre prestación de servicios, y además refuerza los derechos y garantías de los consumidores al establecer un marco de referencia de toda la normativa reguladora del sector servicios. En dicha ley se obliga a las administraciones a revisar sus procedimientos de autorización de las actividades. De ahí que en todas las comunidades se documenten textos posteriores a esta fecha, con la inclusión de formularios de Declaración responsable que los establecimientos hoteleros deben completar para iniciar sus actividades.

14 Esto se comprobó también en un análisis anterior, centrado en las denominaciones de los establecimientos hoteleros en España (Sanmartín 2012).

15 Entendemos por definición, la expresión por al que se describe un sentido. En lexicografía es el procedimiento tradicional por el que se cataloga cada una de las acepciones de la entrada; y por acepción, el s entido consolidado por el uso y aceptado por una comunidad de hablantes (Medina, 2003: 127-146).

16 Los ejemplos de uso pueden ser muy variados en función del género discursivo seleccionado. Si se optara por reproducir textos de foros de opinión y blog, el registro se aproximaría a lo coloquial y las descripciones serían muy diferentes, ya que todo pasa por el filtro enunciador del sujeto: Muy buen hotel que nos permitió pasar una semana inolvidable en la Riviera Maya. La habitación junior suite enorme, con cama king size y balcón con mesita y dos sillones. Buen colchón y amplio baño. Por esforzarme y sacar defectos./ Nos ha gustado mucho todo, 
solo tengo una pega el servicio e instalaciones es genial, pero es chocante que aparcar en mi caso una motod, en el parking cueste 10 euros diarios, un poco cutre para un hotel de esa categoría.

17 También sería interesante señalar la frecuencia léxica de la unidad en cuestión para determinar si presenta un uso generalizado o restringido.

18 Tómese como ejemplo el empleo actual de la voz single como equivalente de soltero o soltera. Al igual que en el ámbito de la gestión y promoción del alojamiento, el análisis de la voz en el contexto de uso nos permitiría descubrir ciertas connotaciones semánticas distintas entre ambas palabras.

19 Resulta sorprendente la falta de acuerdo en torno al concepto de suite, esto es, si se requiere que sea una habitación con salón separado o dos habitaciones con salón separado. Esta última definición se encuentra en A. Blasco (coord.) (2006: 78) y no coincide con los ejemplos de uso, texto didáctico dirigido a un especialista en formación: "1. Suite. Como mínimo contará con dos habitaciones con sus respectivos baños y un salón común. Junior suite. Se trata de una habitación doble con salón. 3. Habitación individual (SB). Está compuesta por una sola cama. Habitación doble. (DB) Cuenta con dos camas o capacidad para dos personas, pudiendo existir: a) Twin; dos camas individuales juntas o separadas. B) Cama de matrimonio: la doble mide 1,35 metros de ancho, la queen, 1,50 y la King, 2." En el texto se indican una serie de siglas no incorporadas a nuestra descripción. Hemos comprobado que las suites pueden tener uno o dos dormitorios; de hecho, así se promocionan en algunos hoteles de la cadena Melià: máster suite un dormitorio (máster suite dos dormitorios). http://www.gran-meliapalacio-de-isora.com/es/habitaciones/suite-familiar.php

Recibido:

$23 / 11 / 2011$

Reenviado:

$18 / 12 / 2012$

Aceptado:

$29 / 12 / 2012$

Sometido a evaluación por pares anónimos 